\title{
Reduction of the Pressurization System Final Mass for a Modern Rocket Launcher
}

\author{
Yurii Mitikov ${ }^{1} \mathbb{D}$, Olexiy Shynkarenko ${ }^{2, *}$ (D)
}

1.Oles Honchar Dnipro National University Rỏ - Jet Propulsion System Design Department - Dnipro - Ukraine. 2.Universidade de Brasília Rọ - Departamento de Engenharia Aeroespacial - Laboratório de Propulsão Química - Brasília/DF - Brazil.

*Correspondence author: olexiy@aerospace.unb.br

\begin{abstract}
The work focuses on optimizing the pressurization system's operating performance for a fuel tank of a turbo-pumped liquid propellant rocket engine. This system is the most complex and expensive in a medium-size launch vehicle, after the engine. A new patented methodology of reducing the final mass of a rocket stage is proposed, studied, and validated. The application of the proposed method is efficient at the end of the engine operation sequence during the throttling regime. The calculation method of the helium excess in the high-pressure cylinders uses the model of the real gas. It also involves empirical relations describing nonstationary heat and mass transfer in the system. As an innovative technical solution, the authors propose to estimate excess gas discharge from tanks and cylinders after the engine's last throttling. The practical application of the research allows saving tenths of kilograms of a payload with the implementation of simple modification in the launcher control program. The research results demonstrated the effectiveness of the methodology on the example of the RD-171 fuel tank pressurization system.
\end{abstract}

Keywords: Dry mass reduction; Pressure reduction; Liquid propellant rocket engines; Helium; Pressure regulators; Propellant tanks.

\section{INTRODUCTION}

A few new development trends are well-settled within modern rocket and space technology. First is a demand for space technology progress. The second is yearly launch counts a minor increase among all countries in the world. According to the Space Launch Report (Kyle 2020), there have been made 114 launch attempts in 2019 with 10 failures. The reason is that the satellites are getting more compact, and their orbit lifetime grows due to satellite technologies' improvement. A medium-sized launch vehicle can simultaneously launch to orbit up to a hundred satellites (Datta 2021). The third trend is space commercialization, where multiple private companies worldwide are offering their services.

The trends outlined above have boosted the rocket launch market competitiveness. That resulted in additional effectiveness indicators to be born. One of the principal criteria is the cost of bringing a payload to orbit (Cás 2019). The time when governments had competed in entering space at any price for political reasons is far behind. At the same time, the mission reliability must be no less than already widely accepted. There are several ways to a rocket launch cost reduction. One way is to explore new and revolutionary technical opportunities, and another one is to modernize existing systems. New innovative technologies implementation in the aerospace field requires rigorous experimental development. It requires both time as well as high costs. Nowadays, modern rocket launchers still have some legacy systems with no design adjustments in decades. One can find new reserves, and excessive

Received: Feb. 27, 2021 | Accepted: Oct. 20, 2021

Peer Review History: Single-Blind Peer Review

Section editor: Juan Pablo Salazar 
mass could reduce after a rigorous revision of such components. However, some system optimizations might not require costly testing and redesign. These optimizations pose both scientific and technical innovation interests.

The most expensive and technically complicated launch vehicle part is the liquid rocket engine (further - engine). The second most costly part is the helium pneumohydraulic pressurization system, according to Degtyarev et al. (2014). These systems are the most widespread and used in the following launch vehicles: Falcon-9, Electron, Atlas-V, Antares, Angara (A comprehensive... 2020). The central unit in those systems is the pressurization system of the fuel tank. Therefore, it is rational to explore reserves, first of all in rocket launchers' most expensive and sophisticated components.

The historical analysis of the engine working cycle demonstrates potential areas for their improvement. Engines for lower stages designed in the late 1960 s worked up to $95 \%$ of the time in their nominal regime. RD-107, RD-108, and F-1 are typical examples of such motors. Therefore, the defining criteria for the pressurization system design are the end of engine operation. At this moment, the impact of the fuel column height $h$ on the input pressure consumed by the pump $p_{\text {inp }}$ is minimal, whereas the hydraulic pressure loss remains nominal, according to Eq. 1., Belyaev (1976) have found the minimal required gas pressure inside the tank:

$$
\begin{gathered}
\mathrm{p}_{\mathrm{MN}}=\mathrm{p}_{\text {inp }}+\Delta \mathrm{p}_{\text {loss }}-\rho \mathrm{n}_{\mathrm{x}} \mathrm{h} \\
\mathrm{p}_{\text {inp }}=\mathrm{p}_{\mathrm{s}}\left(\mathrm{t}_{\text {inp }}\right)+\Delta \mathrm{p}_{\text {acr }}
\end{gathered}
$$

where $P_{i n p}$ is the required input engine pressure, $\Delta p_{a c r}$ is the anticavitation pump reserve, $h$ is the fuel level in the tank, $\rho$ is the fuel density, $n_{\mathrm{x}}$ is the longitudinal acceleration of the rocket (Eq. 2).

Katorgin (2004) shows that the modern engine for the first stage of the rocket launcher can provide a deep in-flight throttling (Fig. 1). Nowadays, this requirement became technically achievable. For example, for the engine RD-191, the throttling intensity may reach up to $30 \%$. Nevertheless, the settled pressurization system design guidelines do not entirely utilize that capability.

(a)

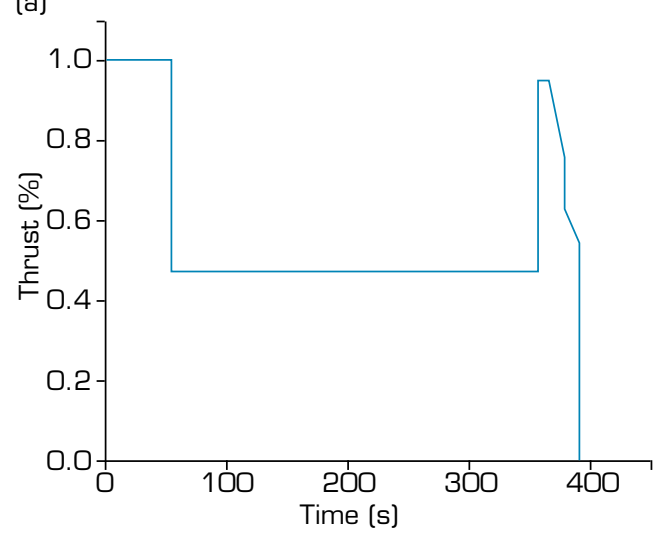

(b)

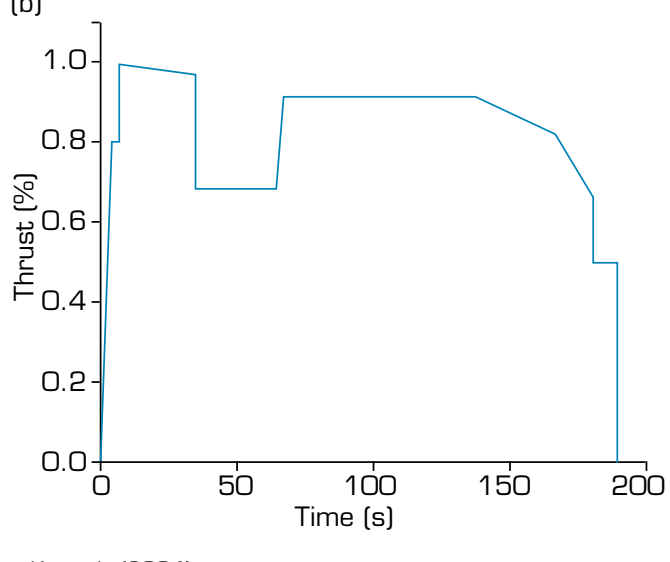

Source: Adapted from Katorgin [2004).

Figure 1. Operation diagram of the RD-180 for the launch vehicle Atlas-5 400 series (a), 500 series (b).

Technical literature with a focus on pressurization systems discusses primarily methodological problems. They refer to the theoretical, numerical, and experimental studies of the fuel tank's internal flow processes and optimize the propellant tank's geometry.

Holt et al. (2000) studied an integrated generalized simulation program model for the helium pressurization system's fluid system, where they predicted pressure and temperature values correlate with data collected experimentally. The study of Kim et al. (2012) describes transient thermal behavior in the cryogenic oxidizer tank for the liquid propulsion system. In the fuel tank 
during helium input pressure, growth was investigated with close attention. The minimum helium solubility within oxygen is detected. Wang et al. (2013) present the original fluid dynamic model. The heat exchange inside the tank and outer aerodynamic heating are evaluated side-by-side. Naoumov et al. (2019) investigated the high pressurized hot gas input into the free tank volume. Tank internal processes have high variations due to the complex gas flow models.

Wang et al. (2015) have made an experimental investigation on the cryogenic tank operation during the high-temperature pressurization by helium. The research presented beneficial experimental results. It allows the pressurization system design and optimization with a high-temperature gas supply. Park et al. (2005) described a method to determine the optimal size of a liquid helium tank and presented a set of results under a given set of requirements.

In et al. (2005) studied an electric heater that makes the pressurization system of a liquid propellant rocket very simple and reliable by reducing the volume and the weight of the pressurant tank. The research investigated the effect of the heating power on the pressurization performance through the experiment.

The studies focused on improving the tank pressurization systems' calculation methodology, as follows from the literature analysis. Until now, there was no research found on estimating the demand for gas pressure in fuel tanks at various points during the engine operation to reduce the final mass of a lower stage of a launcher.

This study aims to decrease the pressurization systems' weight for the modern throttleable engine's fuel tank. The particular objectives of this work are:

- To find the actual gas pressure-demand within a fuel tank of a modern engine;

- Taking advantage of engine throttling for existing and in-design pressurization systems;

- Defining reduction method of a rocket stage final mass for given technical specifications.

The practical application of current research allows saving tenths of kilograms of a payload with the simple modification in the launcher control program.

\section{METHODOLOGY}

The rocket engine RD-171 (A comprehensive... 2020) will be used as an example to describe a calculation methodology that allows reducing the lower stage weight. The analysis of the RD-171 shows that the injector head pressure (Fig. 2) is entirely similar to the produced thrust (Katorgin 2004).

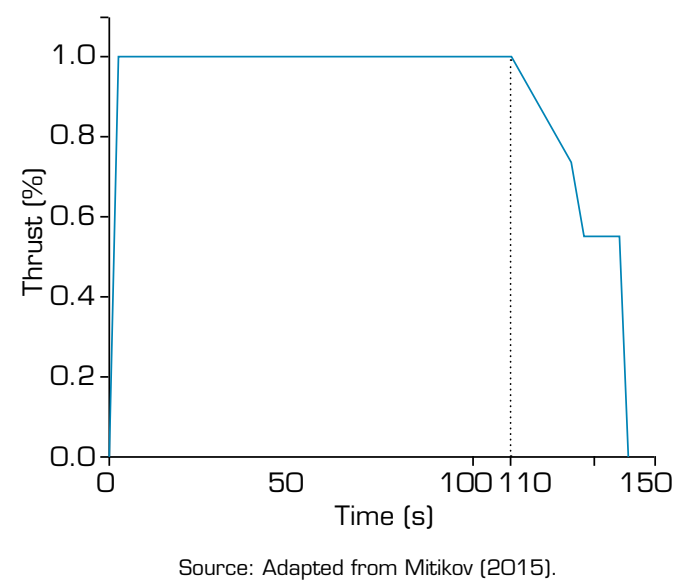

Figure 2. Pressure (thrust) diagram on the injector head of the RD-171.

Figure 2 highlights that the engine RD-171 throttles only once, starting from the $110^{\text {th }}$ second of the flight. Here and further, zero time corresponds to the launch vehicle's start, and $P_{\mathrm{NOM}}$ is the engine's nominal thrust defined as (Eq. 3):

$$
\overline{\mathrm{P}}=\mathrm{P}(\mathrm{t}) / \mathrm{P}_{\mathrm{NOM}}
$$


The fuel tank gas pressure $P_{M O D}$ obtained by the mathematical model (Mitikov 2015) is shown in Fig. 3. It also represents the fuel tank gas pressure $P_{E X P}$ based on six in-flight tests. The comparison shows decent modeling accuracy; that is a statement the authors rely further on upon. Figure 3 also shows the required fuel tank gas pressure $P_{M N}$ for RD-171 during the flight, according to Katorgin (2004). Here, the region SF corresponds to the safety valve adjustment.

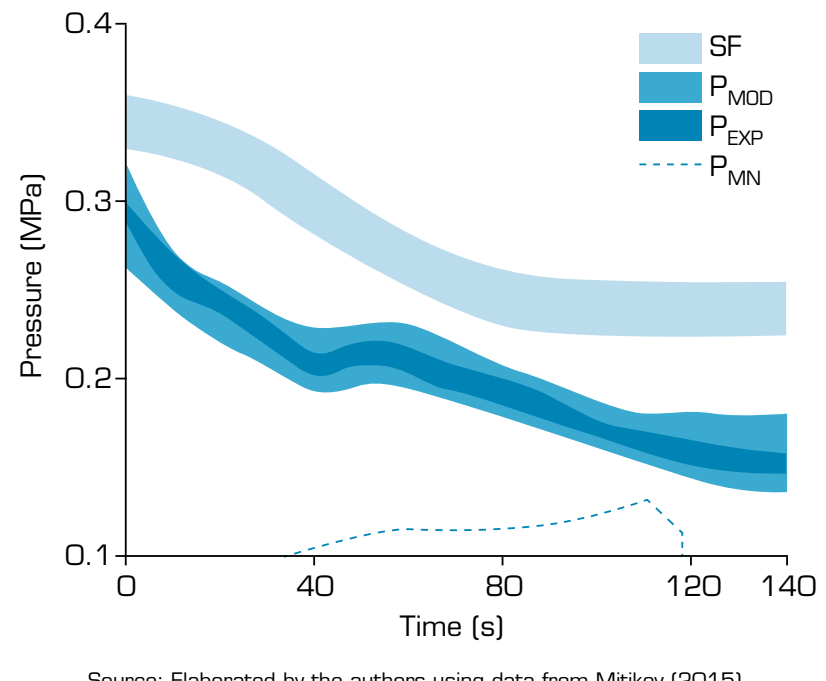

Figure 3. Fuel tank pressure for RD-171.

Analysis of the in-flight demand for gas pressure in the fuel tank shows the following. With the engine throttling from $110 \mathrm{~s}$ of flight, the fuel tank's required gas pressure drops sharply. The pressure losses of fuel along the paths $\Delta P_{H L}$ decrease proportionally to the second power of the velocity (flow rate) of the component, according to the relation of Darcy-Weisbach:

$$
\Delta \mathrm{P}_{\mathrm{HL}}=\lambda \frac{1}{\mathrm{~d}} \cdot \frac{\mathrm{V}^{2}}{2 \mathrm{~g}} \cdot \rho
$$

where $\lambda$ is the hydraulic friction coefficient, $l$ and $d$ are the length and diameter of the pipeline, respectively, $V$ is the average flow velocity of propellant, $g$ is the acceleration of gravity.

In this process, a decrease in overload $n_{\mathrm{x}}$ with a small fuel level $h$ before entering the pump affects only the first degree, according to Eq. 1.

When the RD-171 engine runs without throttling, the tank's required gas pressure would only increase after $110 \mathrm{~s}$ of flight. It happens due to: (i) a further decrease in the fuel level contribution to the engine inlet pressure; (ii) hitting the upper heated fuel layer at the engine inlet that increases the saturated vapor pressure.

The second factor is insignificant for fuels like RP-1. However, it is definitive for the oxidizer. When the engine RD-171 switches off after the throttling regime, there is an excess of at least $0.1 \mathrm{MPa}$ of gas pressure in the tank. Unfortunately, it is not possible to specify this value more accurately. In Mitikov's (2015) work, the tank's required gas pressure is below $0.1 \mathrm{MPa}$ at the end of the engine's operation was not defined due to another research goal. Such an example once again demonstrates one of the old pressurization system design patterns.

The analysis of the described picture derives a reasonable outcome. In the second half of RD-171 operation, there is an excess gas pressure in the fuel tank starting from the throttling regime and before its shutdown. This example confirms the new possibilities of reducing the weight of a launcher's first stage. It demonstrates the typical situation with the engine's deep throttling at the end of the engine operation. For example, for the Atlas-5 launch vehicle using the RD-180 engine with a heavy payload, the tanks' gas pressure should also drop sharply after its last deep throttling after approximately $170 \mathrm{~s}$ of flight (Fig. 1b). Unfortunately, Katorgin (2004) does not specify the required gas pressure inside the tanks for this case.

The presented situation allows the search of methods to reduce the mass of pressurization systems for all engines with throttling in the second half of their work. Mitikov (2020) studied the pressure dumping method of the excess gas in the tanks to the required 
values. Structurally, this method has a simple, practical implementation. Opening the tank drain valve for a specific time interval solved the problem. Discharge of the gas realized using torqueless valves allows the system's efficiency to be improved. The release of the helium residues from the pressurization system's high-pressure cylinders may improve the technical solution, decreasing the rocket stage's total mass. For example, the pressure in the helium cylinders of the RD-171 fuel tank is about $2 \mathrm{MPa}$ after $110 \mathrm{~s}$ of the flight and about $4 \mathrm{MPa}$ in the oxidizer's cylinders.

Now let's examine a method for calculating the discharge process and the required time interval for which it is necessary to open the drain valve of the fuel tank to relieve excess pressure. As an example, the authors take the first-stage fuel tank of the Zenit launch vehicle. As shown in the diagram (Fig. 4), helium is injected from the cylinders (1) at cryogenic temperature into the fuel tank (6) by the shortest route (3) continuously while the engine is running. The tank, weighing several tons, and fuel, weighing several tens of tons, serve as heat exchangers. Figure 4 also shows the flow control equipment (4), gas inlet (5), drain valve (7), and the stop valve (8). Such schematics are exceptionally effective when the propulsion system operates with the afterburning of an oxidizing gas. It has been implemented at the first and second stages of the Zenit and Mayak launch vehicles, the first stage of the launch vehicle Energia, Antares, Atlas-III, and Atlas-V (A comprehensive... 2020).

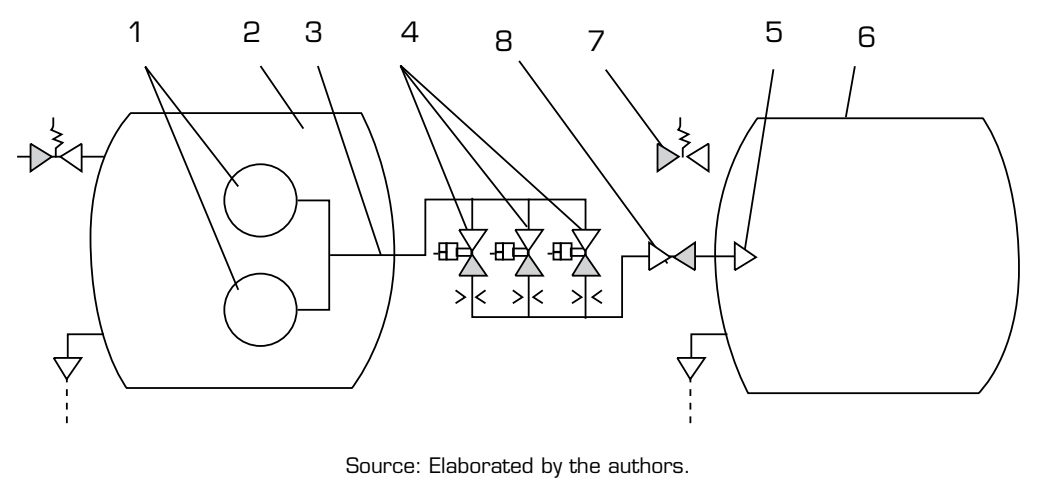

Figure 4. General schematics of the fuel pressurization system of RD-171.

First, we determine the free gas volume of the propellant tank $V$ at the $100^{\text {th }}$ second as shown in Eq. 5:

$$
\mathrm{V}=\frac{\mathrm{mR} \overline{\mathrm{T}}}{\mathrm{P}}
$$

where, $P$ is the gas pressure in the free volume of the tank, $R$ is the helium gas constant (evaporation of the kerosene at a temperature near $200 \mathrm{~K}$ is negligibly small), $\overline{\mathrm{T}}$ is the mass-averaged temperature of helium in the free volume of the tank.

The helium flow $\dot{m}_{S F}(t)$ through the drain valve with the flow area $f_{\mathrm{SF}}$ from the tank into the near-vacuum pressure (critical outflow) is determined by the Saint-Venant-Wantzel formula (Spurk and Aksel 2020). In this case, the ideal gas model can be used as shown in Eq. 6:

$$
\dot{\mathrm{m}}_{\mathrm{SF}}(\mathrm{t})=\frac{2.28 \mathrm{Pf}_{\mathrm{SF}}}{\left(\mathrm{R} \overline{\mathrm{T}}\left[1+5.2 \xi_{\mathrm{SF}}\right]\right)^{0.5}}
$$

where, $\xi_{\mathrm{dv}}$ is the local resistance coefficient of a drain valve.

The only unknown parameter in Eqs. 5 and 6 is the helium mass-averaged temperature in the tank. Due to the intensive gas circulation, vertical thermal stratification in the tank does not happen. When the system injects a relatively small portion (compared to total gas mass) of high-density gas into the tank, its mixing occurs almost immediately (Belyaev 1976). Therefore, the Saint-Venant-Wantzel formula may use the experimentally estimated gas temperature at the tank's upper dome (Fig. 5) (Mitikov 2020). 


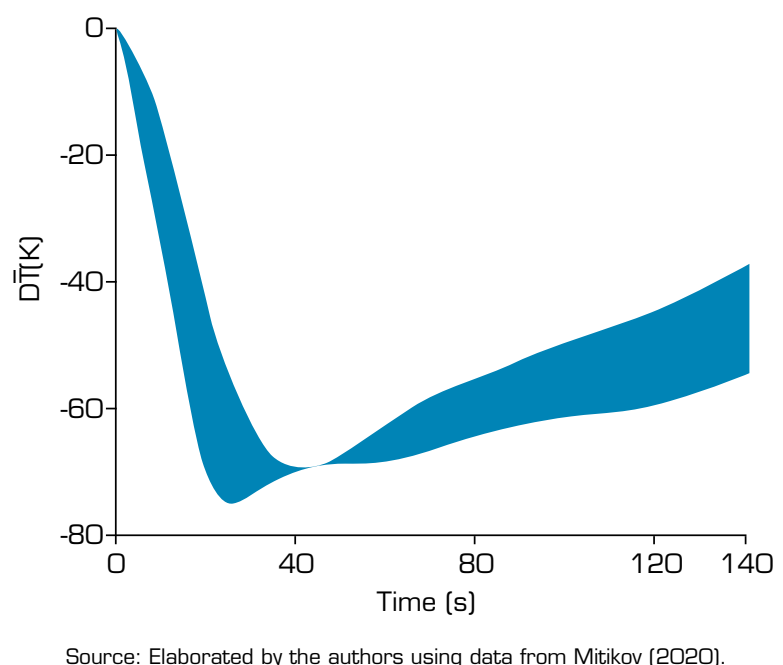

Figure 5. Actual temperature drop (two independent measurements) of the gas at the upper bottom of the RD-171 fuel tank.

On the $110^{\text {th }}$ second of RD-171 operation, the fuel tank gas temperature (Fig. 5) is equal to $218 \mathrm{~K}$. This value is obtained with sufficient accuracy by the methodology of Mitikov (2015). As indicated above, the method is based on previous experimental in-flight data analysis involving fundamental thermodynamic relations.

The gas pressure temporal change in the fuel tank due to the gas extraction $\dot{m}_{D K}$ and injection from the pressurization system $\dot{m}_{P S}$ can be obtained by jointly solving the Clapeyron equation for the ideal gas and the first law of thermodynamics (Eq. 7):

$$
\dot{\mathrm{P}}=\frac{\mathrm{k}-1}{\mathrm{~V}} \cdot\left[\dot{\mathrm{Q}}_{\Sigma}+\frac{\mathrm{k}}{\mathrm{k}-1} \mathrm{R} \overline{\mathrm{T}} \dot{\mathrm{m}}_{\mathrm{CH}}-\frac{\mathrm{k}}{\mathrm{k}-1} \mathrm{R} \overline{\mathrm{T}} \dot{\mathrm{m}}_{\mathrm{DK}}-\frac{\mathrm{k}}{\mathrm{k}-1} \mathrm{P} \dot{\mathrm{V}}\right]
$$

where $V$ is the free gas volume in the tank, $k=$ const $=1.66$ is the specific heat ratio of helium (evaporation of kerosene is negligible, considering low temperature), $\dot{\mathrm{Q}}_{\Sigma}$ is the total heat flow to the gas from surrounding walls, $\overline{\mathrm{T}}$ is the average temperature of the gas inside the tank, and $\dot{V}$ is the fuel volumetric flow rate.

The heat flow balance to the pressurization gas in the tank, excluding condensation, evaporation of propellant, and chemical reactions in the free volume of the tank (Eqs. 8-10) is equal to:

$$
\begin{gathered}
\dot{\mathrm{Q}}_{\mathrm{L}}=\dot{\mathrm{Q}}_{\mathrm{L}}+\dot{\mathrm{Q}}_{\mathrm{W}} \\
\dot{\mathrm{Q}}_{\mathrm{L}}=\alpha_{\mathrm{L}} \Delta \mathrm{T}_{\mathrm{L}} \mathrm{F}_{\mathrm{L}} \\
\mathrm{Q}_{\mathrm{W}}=\alpha_{\mathrm{W}} \Delta \mathrm{T}_{\mathrm{W}} \mathrm{F}_{\mathrm{W}}
\end{gathered}
$$

where, $\dot{\mathrm{Q}}_{L}$ is the heat flow from the propellant to the pressurization gas, $\alpha_{L}$ is the heat transfer coefficient from pressurization gas to the propellant surface, $\Delta \mathrm{T}_{L}=\overline{\mathrm{T}}-\mathrm{T}_{L}$ is the temperature difference between the pressurization gas and the propellant surface, $F_{L}$ is the area of propellant surface, $Q_{w}$ is the heat flow from the pressurization gas to the tank wall, $\alpha_{w}$ is the heat transfer coefficient from pressurization gas to the wall, $\Delta \mathrm{T}_{w}=\overline{\mathrm{T}}-\mathrm{T}_{w}$ is the temperature difference between pressurization gas and the wall, and $F_{\mathrm{w}}$ is the dry area of the wall.

Heat fluxes from the tank wall and free fuel surface to the pressurization gas are determined from the empirical formulas for the heat transfer in natural stationary convection $N u=f(G r, P r)$, according to Belyaev (1976) (Eqs. 11-13).

$$
\mathrm{Nu}=\frac{\alpha \mathrm{d}}{v}
$$




$$
\begin{gathered}
\mathrm{Gr}=\frac{\beta\left(T-\mathrm{T}_{\mathrm{L}}\right) \mathrm{g}}{v^{2}} \mathrm{~d}^{3} \\
\operatorname{Pr}=\frac{v}{\mathrm{a}}
\end{gathered}
$$

where $N u$ is the Nusselt number, $G r$ is the Grashof number, $P r$ is the Prandtl number, $\alpha$ is the heat transfer coefficient, $d$ is the characteristic linear dimension (tank diameter), $v$ is the gas kinematic viscosity coefficient, $\beta$ is the gas volume expansion coefficient, and $a$ is the thermal diffusivity of the gas.

The heat transfer coefficients are defined in Eqs. 14 and 15:

$$
\begin{gathered}
\alpha_{\mathrm{L}}=0.004\left[\frac{\mathrm{P}}{0,5\left(\overline{\mathrm{T}}+\mathrm{T}_{\mathrm{L}}\right)}\right]^{0.7} \cdot\left(\overline{\mathrm{T}}-\mathrm{T}_{\mathrm{L}}\right)^{1 / 3} \\
\alpha_{\mathrm{w}}=0.2\left(\overline{\mathrm{T}}-\mathrm{T}_{\mathrm{w}}\right)^{0.5}
\end{gathered}
$$

The model consists of ordinary differential and algebraic equations. The calculation procedure is as follows. According to Eq. 6, the authors determine the gas mass loss from the tank and the decrease of the tank pressure. Here the authors consider the loss of heat to the boundary surfaces according to Eq. 7. After the first step of integration, the amount of gas remaining in the tank and its average temperature is calculated. The heat balance equation for the tank wall allows to determine the wall massaveraged temperature for the next integration step. The fuel surface temperature can be considered constant and equal to the initial temperature. Its change is insignificant in comparison with other parameters. Then, the calculation repeats until the total integration time is reached.

The system's solution requires a setup of the initial conditions and definition of the temperature dependences and the thermophysical properties of the fuel, helium, and the tank walls' material. The system's numerical integration with the time step of $0.1 \mathrm{~s}$ using the Euler or Runge-Kutta method allows obtaining a satisfactory solution.

The calculation stops when the tank's gas pressure reaches its lower limit $P_{\mathrm{MN}}$ (Fig. 3), determining gas mass in the tank. One may obtain the gas mass-averaged temperature in the tank from calculation or the experiment (Fig. 5). The drain valve is open until the tank pressure drop reaches a desirable value.

The procedure of helium release from cylinders occurs according to the following algorithm. After the pressure release starts, the cylinders' valves do not need to be closed. When the gas pressure in the cylinders reaches a specific level, the stop valve (8) closes (Fig. 4), and the flow finishes. The cylinder discharge is determined by a similar method to the tank discharge explained above.

There are two commonly used calculation methods of helium discharge. The first one takes into account the heat exchange of helium with the cylinder. The second one, less accurate, assumes a constant temperature of helium in the cylinders. For any of these approaches, first, the total mass of helium in the cylinder before the throttling starts should be determined. Following Eq. 5, it is necessary to calculate the pressure and temperature variation of helium in the cylinder (Mitikov 2015).

The behavior of the gas pressure in the cylinders during the system operation can be calculated as follows. Differentiating the internal energy equation applied to a cylinder by a system's operating time and involving the first law of thermodynamics, the authors obtain Eq. 16, as follows:

$$
\dot{\mathrm{P}}_{\mathrm{c}}=\frac{\mathrm{z}(\mathrm{k}-1)}{\mathrm{V}_{\mathrm{c}}} \cdot\left[\dot{\mathrm{Q}}_{\mathrm{c}}+\frac{\mathrm{k} \dot{\mathrm{m}}_{\mathrm{c}} \mathrm{R} \mathrm{T}_{\mathrm{c}}}{\mathrm{k}-1}\right]+\frac{\dot{\mathrm{z}}}{\mathrm{z}} \mathrm{P}_{\mathrm{c}}
$$

where, $V_{\mathrm{c}}=$ const is the cylinders' internal volume, $z$ is the helium compressibility coefficient, $\dot{Q}_{c}$ is the heat flux from the cylinder wall to the gas, $\dot{m}_{c}$ is the gas mass flow rate, $T_{\mathrm{c}}$ is the gas temperature in the cylinder, $P_{\mathrm{c}}$ is the absolute pressure of the gas in the cylinder. 
The adiabatic coefficient of helium in the general case for a real gas depends on temperature and pressure $k=f\left(T_{\mathcal{c}} P_{c}\right)$. However, in the studied range of temperatures from 40 to $90 \mathrm{~K}$ and pressures from 0.4 to $23.0 \mathrm{MPa}$, this value is practically constant (Istomin 1997). To determine the compressibility coefficient of helium, one can use the confirmed relationship (Shevchenko et al. 2018). The estimated error in Eq. 17 is near $1 \%$ in the range of helium temperatures from 40 to $90 \mathrm{~K}$ and pressures from 1 to $30 \mathrm{MPa}$.

$$
z=\left(0,14 \cdot 10^{-5} / T_{c}+5 \cdot 10^{-10}\right) \cdot P_{c}+0.97
$$

When the helium outflow from the cylinders is critical, the mass flow rate could be determined by Eq. 1. The reduced coefficient of resistance of the entire discharge system should be used as the global resistance coefficient. The amount of gas discharged from the tank can be calculated by the equation of state (Eq. 18):

$$
\Delta \mathrm{m}=\frac{\mathrm{V}}{\mathrm{RT}}\left(\mathrm{P}-\mathrm{P}_{\mathrm{k}}\right)
$$

where, $P_{\mathrm{k}}$ is the gas pressure in the tank at the end of the gas relief. For example, having the $V=80 \mathrm{~m}^{3}, D P=10^{5} \mathrm{~Pa}$, and $T=218 \mathrm{~K}$, we receive $D m=17.7 \mathrm{~kg}$.

\section{RESULTS}

Calculations of the RD-171 fuel by the proposed method tank showed the following. The final gas mass can be lowered by approximately $23.4 \mathrm{~kg}$ by relieving $0.1 \mathrm{MPa}$ of pressure from the fuel tank. In an actual flight, at the end of the RD-171 engine operation, the tank pressure can be reduced by more than $0.1 \mathrm{MPa}$. In such a way, mass saving could be more prominent. To implement this proposal, just two commands from the control system are sufficient- to open the drain valve and close it. The proposed solution can be strengthened by dumping the residual helium pressure from the cylinders. The effect of the technical solution described will be more significant with a deeper engine throttling in the second half of its operation.

\section{CONCLUSIONS}

A new method of estimating the demand for overflow gas for rocket engines with throttling in the second half of their operation is proposed and analyzed. It has shown that the need for boost gas pressure in the tanks commonly drops significantly after the last throttling of the engine. Such a solution considers the discharge of excess gas from tanks and cylinders of the pressurization system overboard. The reduction in the final stage mass is several tens of kilograms. Nevertheless, the cost of implementing this solution is also minimal.

\section{AUTHOR'S CONTRIBUTION}

Conceptualization: Mitikov YA; Formal Analysis: Mitikov YA, Shynkarenko O; Investigation: Mitikov YA; Methodology: Mitikov YA, Shynkarenko O; Resources: Shynkarenko O; Validation: Mitikov YA, Shynkarenko O; Visualization: Mitikov YA, Shynkarenko O; Writing - Original Draft: Mitikov YA; Writing - Review \& Editing: Shynkarenko O.

\section{DATA AVAILABILITY STATEMENT}

All data sets were generated or analyzed in the current study. 


\section{FUNDING}

Not applicable.

\section{ACKNOWLEDGMENTS}

Not applicable.

\section{REFERENCES}

A comprehensive list of suborbital space launches [Internet]. JSR Launch Vehicle Database. 2020. [accessed 2021 Mar 1]. http://www.planet4589.org/space/lvdb/

Belyaev NM (1976) [Boost systems of rocket fuel tanks]. Moscow: Mechanical engineering. https://www.twirpx.com/ file/2093629/. In Russian.

Cás PLK, Veras CAG, Shynkarenko O, Leonardi R (2019) A Brazilian space launch system for the small satellite market. Aerospace 6(11):123. https://doi.org/10.3390/aerospace6110123

Datta A (2021) \#Launch143: SpaceX breaks ISRO record of most satellites on a single rocket. Geospatial World. [accessed 2021 Mar 1]. https://www.geospatialworld.net/blogs/most-satellites-on-a-single-rocket-spacex-set-to-break-isros-record/

Degtyarev AV, Kushnarev AP, Popov DA, Poluyan NV, Aksenenko AV, Yu E (2014) [Ultra-small class space rocket]. [Space Technology, series Missile Armament] 1:14-20. In Russian.

Holt K, Majumdar A, Steadman T, Hedayat A (2000) Numerical modeling and test data comparison of propulsion test article helium pressurization system. Paper presented at: 36th AIAA/ASME/SAE/ASEE Joint Propulsion Conference and Exhibit; Las Vegas, United States of America. https://doi.org/10.2514/6.2000-3719

In S, Jeong S, Kim Y, Cho K-J, Oh S-H (2005) Experimental Investigation of Liquid Helium Pressurization Method for Liquid Propellant Rocket. JSME Int J Ser B Fluids Therm Eng 48(2):300-304. https://doi.org/10.1299/jsmeb.48.300

Istomin VA (1997) [Isentropic properties of real gas: definitions and fundamental relations]. [J Phys Chem] 71(6):998-1003. In Russian.

Katorgin BA (2004) [Prospects for creating powerful liquid-propellant rocket engines]. [Bulletin of the Russian Academy of Sciences] 74(3):499-506. In Russian.

Kim KH, Ko H-J, Kim K, Jung Y-S, Oh S-H, Cho K-J (2012) Transient thermal analysis of a cryogenic oxidizer tank in the liquid rocket propulsion system during the prelaunch helium gas pressurization. J Eng Thermophys 21(1):1-15. https://doi. org/10.1134/S1810232812010018

Kyle E (2020) 2020 Space Launch Report. Space Launch Report. [accessed 2021 Feb 20]. http://www.spacelaunchreport.com/ $\log 2020 . h$ tml

Mitikov, YA (2015) Kerosene fuel tank super-cold pressurization system parameters mathematical modeling. Kosm nauka tehnol 21(5):43-47. https://doi.org/10.15407/knit2015.05.043

Mitikov YO (2020) [The methodology foundation for designing and upgrading fuel tank engine pressurization systems] 
(Doctoral dissertation). Dnipro: Oles Honchar Dnipro National University. In Russian.

Mitikov YO, Tkachuk OY (2020) [Patent request: Method of supercharging the fuel tank of the propulsion system of the launch vehicle], Application No. a201908058 Ukraine, dated July 12, 2019. B64D 37/00, F02K 9/00. Applicant Mitikov YO.

Naoumov VI, Krioukov VG, Abdullin AL, Demin AV (2019) Pressurization of Liquid Propellant Rocket Engine Tanks. Cambridge: Cambridge University Press. Chapter 9, Chemical Kinetics in Combustion and Reactive Flows: Modeling Tools and Applications, p. 334-379. https://doi.org/10.1017/9781108581714.009

Park YM, In S, Jeong S (2005) The Size Optimization of the Liquid Helium Pressurant Tank for Liquid Propellant Rocket. Key Eng Mater 277-279:776-782. https://doi.org/10.4028/www.scientific.net/kem.277-279.776

Shevchenko SA, Konokh VI, Mitikov YA, Grigoriev AL (2018) Universal orthometric real gas equation of state for modeling processes in rocket-and-space technology units. Bulletin of NTU HPI, series of Mathematical Modeling in Engineering and Technology 27(1303):134-148.

Spurk JH, Aksel N (2020) Fluid Mechanics. Cham: Springer. https://doi.org/10.1007/978-3-030-30259-7

Wang L, Li Y, Jin Y, Ma Y (2015) Experimental investigation on pressurization performance of cryogenic tank during hightemperature helium pressurization process. Cryogenics 66:43-52. https://doi.org/10.1016/j.cryogenics.2014.12.001

Wang L, Li Y, Zhao Z, Liu Z (2013) Transient thermal and pressurization performance of $\mathrm{LO}_{2}$ tank during helium pressurization combined with outside aerodynamic heating. Int J Heat Mass Transf 62:263-271. https://doi.org/10.1016/j. ijheatmasstransfer.2013.03.021 